- Communication-

\title{
Enhancement of the Photocatalytic Activity of CdS Powder by Heat Treatment with Potassium Bromide
}

\author{
Koichi KOBAYAKAWA, Takashi INOUE, Yuichi SATO \\ and Akira FUJISHIMA*
}

Received February 4, 1993 ; Accepted March 25, 1993

\section{INTRODUCTION}

In the previous paper', we reported that the heat treatment of cadmium sulfide (CdS) powder with potassium chloride $(\mathrm{KCl})^{2}$, was a useful method to obtain superior CdS photocatalyst for hydrogen production from sodium sulfite solution. We report here that more superior cds photocatalyst is obtained by heat treatment with potassium bromide(KBr).

\section{EXPERIMENTAL}

The starting CdS amorphous powder having a specific surface area (S) of $117 \mathrm{~m}^{2} \mathrm{~g}^{-1}$ was prepared by chemical precipitation and ground to under 100 mesh. It was mixed with $\mathrm{KBr}$ powder that had been ground to under 100 mesh and then heated in an electric furnace. After heating, the resulting particles were put into distilled water to remove $\mathrm{KBr}$ and dried at $110^{\circ} \mathrm{C}$. The $\mathrm{S}$ of the samples was determined by using the BET method with nitrogen as the adsorbent.

Department of Applied Chemistry, Faculty of Engineering, Kanagawa University ( 3-27-1, Rokkakubashi, Kanagawa-ku, Yokohama 221 Japan ) *Department of Synthetic Chemistry, Faculty of Engineering, The University of Tokyo(7-3-1, Hongo, Bunkyoku, Tokyo 113 Japan)

Key Words : Cadmium Sulfide, Photocatalyst, $\mathrm{kBr}$ Heat Treatment
A $0.5 \mathrm{~g} \mathrm{CdS}$ sample was loaded with 2 wt\% platinum black by shaking and dispersed into $70 \mathrm{~cm}^{3}$ of 1 mol $\mathrm{dm}^{-3} \mathrm{Na}_{2} \mathrm{SO}_{3}$ solution adjusted to $\mathrm{pH}$ 8.0 with boric acid and then deaerated. The magnetically stirred solution containing CdS powder was irradiated using a $400 \mathrm{~W}$ xenon arc lamp. The amounts of hydrogen produced after $6 \mathrm{~h}$ irradiation were compared to determine the photocatalytic activity. A ferrioxalate actinometer and an interference filter were used for the quantum yield measurements.

3 RESULTS AND DISCUSSION

The dependencies of $S$ and the photocatalytic activity of the samples obtained with a mixing ratio of $\mathrm{KBr}$ to CdS of 1.0 and for $2 \mathrm{~h}$

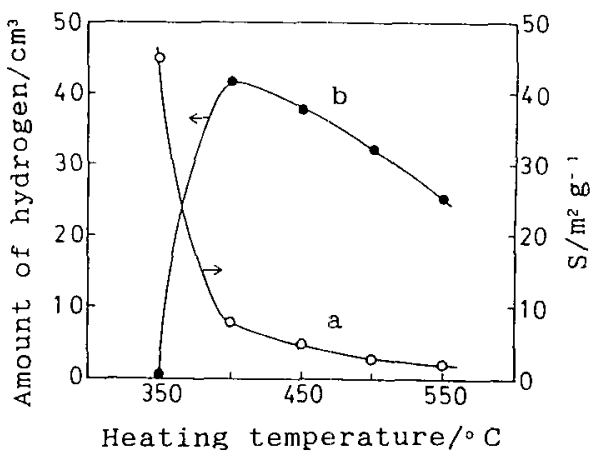

Fig. 1 Dependencies of $S$ (curve a) and the photocatalytic activity (amount of hydrogen gas evolution, curve b) on the heating temperature with a $\mathrm{KBr}$ mixing ratio of 1.0 for $2 \mathrm{~h}$ heating 
heating on heating temperature are shown by curves $a$ and $b$ in Fig. 1 .

As the temperature increased, $\mathrm{S}$ remarkably decreased owing to crystalization. However, the heat treatment at $350^{\circ} \mathrm{C}$ gave a slight improvement in activity since the temperature was low for inducing the crystal growth reactions. Indeed, the sample obtained at $350^{\circ} \mathrm{C}$ is amorphous. The heating temperature of $400^{\circ} \mathrm{C}$ gave a superior activity. A further rise in heating temperature decreased the activity, though samples have a small $\mathrm{S}$ and consist of crystalites.

The study for the effect of $\mathrm{KBr}$ ratio on the activity showed that the ratio of $\mathrm{KBr}$ from 0.75 to 1.25 was effective for superior activity when they were treated at $400^{\circ} \mathrm{C}$ for $2 \mathrm{~h}$. By increasing the heating time at $400^{\circ} \mathrm{C}$ with the $\mathrm{KBr}$ ratio of $1.0, \mathrm{~s}$ decreased. On the other hand, the activity slightly increased at $4 \mathrm{~h}$ and then decreased gradually with heating time. During heat treatment at $450^{\circ} \mathrm{C}, \mathrm{S}$ significantly decreased with time and the activity was also reduced.

Figure 2 is the relationship between $S$ and the photocatalytic activity for all samples obtained in this study. The activity has a maximum around $7 \mathrm{~m}^{2} \mathrm{~g}^{-1}$. The most active cds photocatalyst, which was obtained by the heat treatment with a $\mathrm{KBr}$ mixing ratio of 1.0 at $400^{\circ} \mathrm{C}$ for $4 \mathrm{~h}$, showed the quantum yield of 0.31 for $460 \mathrm{~nm}$ light. This value is the double of the highest quantum yield for the sample having an $S$ of $0.8 \mathrm{~m}^{2} \mathrm{~g}^{-1}$ that obtained by heat treatment using $\mathrm{KCl}^{1}$, and consisted of micro crystallites.

Reber et al. ${ }^{3}$ ' reported that the activity decreased with increasing

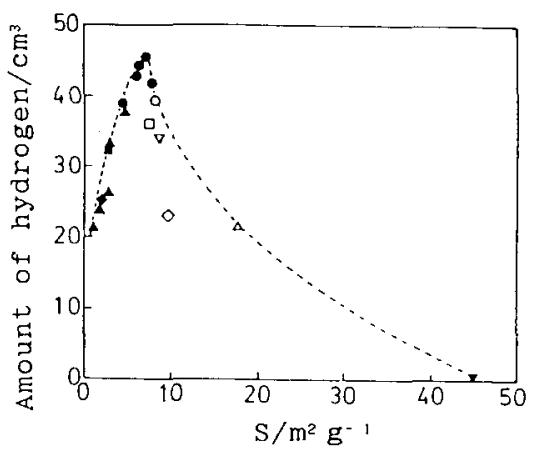

Fig. 2 Relationship between $S$ and the photocatalytic activity for all samples obtained in this study.

$$
\mathrm{KBr} \text { ratio, Temp. }\left({ }^{\circ} \mathrm{C}\right), \mathrm{Time}(\mathrm{h})
$$

$\Delta: 0.25 \quad 400 \quad 2$

$\nabla: 0.50 \quad 400 \quad 2$

$0: 0.75 \quad 400 \quad 2$

- : $1.0 \quad 400 \quad 2-10$

口: $1.5 \quad 400 \quad 2$

$\diamond: 2.0 \quad 400 \quad 2$

$\nabla: 1.0 \quad 350 \quad 2$

$\Delta: \begin{array}{lll}1.0 & 450 & 2-10\end{array}$

a: $1.0 \quad 500 \quad 2$

- $1.0 \quad 550 \quad 2$

S and became negligible above $7 \mathrm{~m}^{2}$ $\mathbf{g}^{-1}$. In our result, the activity increased with increasing $S$ up to 7 $\mathrm{m}^{2} \mathrm{~g}^{-1}$. This result will be due to the increase of the amount of active center or the decrease of crystal defect which acts as a recombination center. In the higher $S$ region ( $\left.>7 \mathrm{~m}^{2} \mathrm{~g}^{-1}\right)$, our result agrees with that of Reber et al. A further investigation is necessary to account for this relationship.

\section{REFERENCES}

1) K.Kobayakawa, T.Miura, A.Suzuki, Y.Sato and A.Fujishima, Solar Energy Mater., Submitted.

2) F.Nakahara and A.Nagae, Zairyou, $19,528(1970)$.

3) J.-F.Reber and M.Rusek, J.Phys . Chem., 90, 824(1986). 